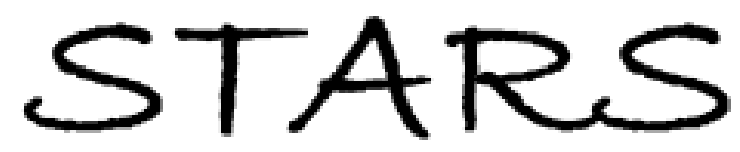

University of Central Florida

STARS

$1-1-2012$

\title{
Enhanced optical limiting in nanosized mixed zinc ferrites
}

\author{
Panit Chantharasupawong \\ University of Central Florida \\ Reji Philip \\ University of Central Florida \\ Tamio Endo \\ Jayan Thomas \\ University of Central Florida
}

Find similar works at: https://stars.library.ucf.edu/facultybib2010

University of Central Florida Libraries http://library.ucf.edu

This Article is brought to you for free and open access by the Faculty Bibliography at STARS. It has been accepted for inclusion in Faculty Bibliography 2010 s by an authorized administrator of STARS. For more information, please contact STARS@ucf.edu.

\section{Recommended Citation}

Chantharasupawong, Panit; Philip, Reji; Endo, Tamio; and Thomas, Jayan, "Enhanced optical limiting in nanosized mixed zinc ferrites" (2012). Faculty Bibliography 2010s. 2384.

https://stars.library.ucf.edu/facultybib2010/2384

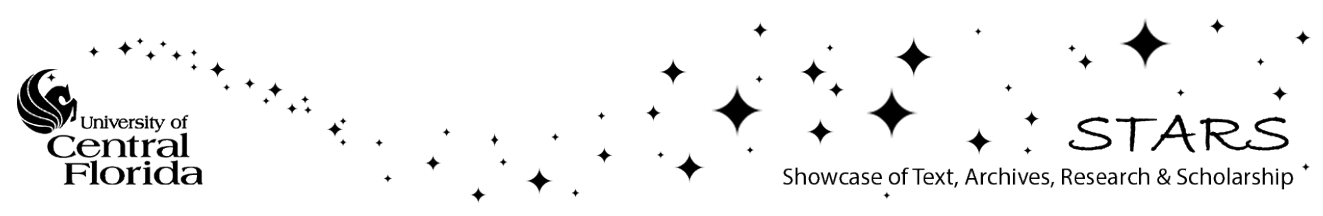




\section{Enhanced optical limiting in nanosized mixed zinc ferrites}

Cite as: Appl. Phys. Lett. 100, 221108 (2012); https://doi.org/10.1063/1.4724194

Submitted: 02 March 2012 . Accepted: 16 May 2012 . Published Online: 30 May 2012

Panit Chantharasupawong, Reji Philip, Tamio Endo, and Jayan Thomas

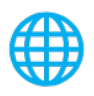

\section{ARTICLES YOU MAY BE INTERESTED IN}

Simultaneous optical and photoacoustic measurement of nonlinear absorption Applied Physics Letters 102, 041116 (2013); https://doi.org/10.1063/1.4789870

Enhanced magnetic properties of $\mathrm{Dy}^{3+}$ substituted Ni-Cu-Zn ferrite nanoparticles Applied Physics Letters 100, 042407 (2012); https://doi.org/10.1063/1.3679688

Nonlinear optical and optical limiting properties of graphene families

Applied Physics Letters 96, 033107 (2010); https://doi.org/10.1063/1.3279148

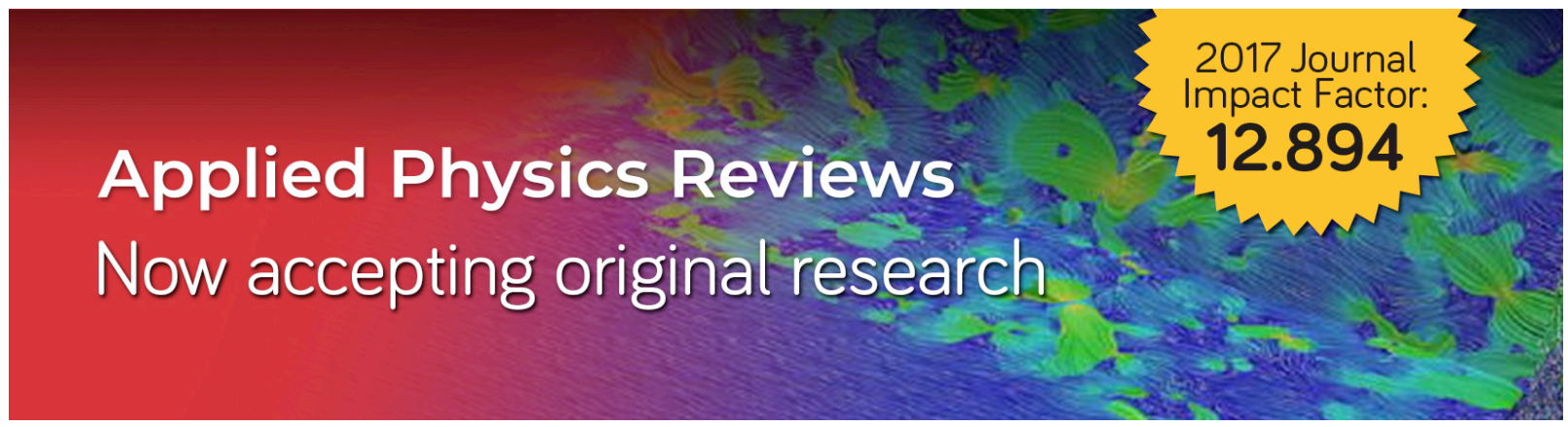




\title{
Enhanced optical limiting in nanosized mixed zinc ferrites
}

\author{
Panit Chantharasupawong, ${ }^{1}$ Reji Philip, ${ }^{2, a)}$ Tamio Endo, $^{3}$ and Jayan Thomas ${ }^{1,2, b)}$ \\ ${ }^{1}$ College of Optics and Photonics, CREOL, University of Central Florida, Orlando, Florida 32826, USA \\ ${ }^{2}$ NanoScience Technology Center, University of Central Florida, Orlando, Florida 32826, USA \\ ${ }^{3}$ Department of Electrical and Electronic Engineering, Mie University, 1577 Kurimamachiya, Tsu, \\ Mie 514-8507 Japan
}

(Received 2 March 2012; accepted 16 May 2012; published online 30 May 2012)

Optical limiting performance of zinc ferrite, nickel zinc ferrite, and copper zinc ferrite nanoparticles is investigated at $532 \mathrm{~nm}$ using 5 nanosecond laser pulses. Enhanced optical limiting is observed in the mixed zinc ferrites, which is attributed to the relative longevity of self-trapped charge transfer states. Samples exhibit absorption saturation followed by a rapid onset of optical limiting as the input fluence is increased. This is advantageous in applications where detector sensitivity should be retained at the maximum value until the input fluence approaches the detector damage regime. The Z-scan results are compared to those measured in $\mathrm{C}_{60}$. $\left({ }^{\circ} 2012\right.$ American Institute of Physics. [http://dx.doi.org/10.1063/1.4724194]

It is known that nanomaterials, in general, exhibit altered physical and chemical properties in comparison to their bulk forms. ${ }^{1}$ This originates from factors associated with size reduction, such as increase in grain boundaries and enhanced surface to volume ratios. Quantum confinement is another aspect that plays an important role in the electrical and optical properties of materials like semiconductor quantum dots. ${ }^{2}$ Magnetic spinel ferrites $\left(\mathrm{M}_{\mathrm{x}} \mathrm{Fe}_{3-\mathrm{x}} \mathrm{O}_{4}\right.$, where $\mathrm{M}=\mathrm{Fe}, \mathrm{Co}, \mathrm{Mn}, \mathrm{Ni}$, or $\mathrm{Zn}$ ) are versatile nanomaterials, which find use in several magnetic and biological applications. These structures are characterized by superparamagnetism and tunable surface properties. Optical nonlinearities in ferrites are relatively unexplored, and reports ${ }^{3-5}$ are rare compared to organics, semiconductors, and metals. Modifications in optical nonlinearity caused by the inclusion of different transition metals into a spinel ferrite system would be of considerable interest owing to applications including optical limiting. Therefore, in the present work, we have studied the nonlinear optical properties of nanosized spinel $\mathrm{Zn}$ ferrite $\left(\mathrm{ZnFe}_{2} \mathrm{O}_{4}\right)$, in comparison to its $\mathrm{Ni}$ and $\mathrm{Cu}$ mixed forms, namely, NiZn-ferrite $\left(\mathrm{NiZnFe}_{2} \mathrm{O}_{4}\right)$ and CuZn-ferrite $\left(\mathrm{CuZnFe}_{2} \mathrm{O}_{4}\right)$, using the open-aperture $\mathrm{z}$-scan technique.

Ferrites are non-conductive ceramic compounds derived from iron oxides such as hematite $\left(\mathrm{Fe}_{2} \mathrm{O}_{3}\right)$ or magnetite $\left(\mathrm{Fe}_{3} \mathrm{O}_{4}\right)$. They are magnetic in nature, and are extensively used for magnetic recording, and in the construction of inductors, permanent magnets, electrical transformers, and millimeter integrated circuits. ${ }^{6}$ Due to their unique nonreciprocal and frequency-selective properties, ferrite devices have played a key role in active aperture radar, microwave, and multifunction systems on defense platforms. ${ }^{7}$ Recently, they have been investigated for magnetic resonance imaging (MRI) ${ }^{8}$ thermal activation therapy, ${ }^{9}$ drug delivery, ${ }^{10}$ and biosensing ${ }^{11}$ applications.

\footnotetext{
a) Permanent address: Raman Research Institute, C.V. Raman Avenue, Sadashivanagar, Bangalore 560080, India.

b) Author to whom correspondence should be addressed. Electronic mail: Jayan.Thomas@ucf.edu.
}

Crystal structure of ferrites can be described as a closepacked assembly of oxygen atoms with metal atoms occupying the interstitial sites. ${ }^{12}$ Spinels are a class of ferrites of general formulation $\mathrm{A}^{2+} \mathrm{B}_{2}{ }^{3+} \mathrm{O}_{4}{ }^{2-}$, which crystallize in the cubic (isometric) crystal system, with the oxide anions arranged in a cubic close-packed lattice. One unit cell of a spinel ferrite contains eight molecules with twenty four metal positions. Of these, eight are tetrahedral sites and the remaining sixteen are octahedral sites. In the case of $\mathrm{Zn}$-ferrite, tetrahedral sites are occupied by $\mathrm{Zn}^{2+}$ ions and octahedral sites by $\mathrm{Fe}^{3+}$ ions. ${ }^{6}$ This type of structure where divalent and trivalent cations occupy tetrahedral and octahedral sites, respectively, is called normal spinel.

In this paper, we investigate the optical limiting properties of spherical nanoparticles of $\mathrm{ZnFe}_{2} \mathrm{O}_{4}$ and its $\mathrm{Ni}$ and $\mathrm{Cu}$ mixed forms, which are well dispersed in toluene. Results are compared to those measured in $\mathrm{C}_{60}$ under identical conditions. $\mathrm{C}_{60}$ was chosen for comparison because it is a benchmark material for optical limiting and is extensively studied in literature. ${ }^{13-15}$ All samples were purchased from Aldrich and used without further purification. The nanoparticles are less than $100 \mathrm{~nm}$ in size, and their SEM images taken on a Zeiss ULTRA-55 FEG SEM are shown in Figure 1. The open aperture Z-scan technique ${ }^{16}$ has been used to determine the optical limiting efficiencies and thresholds, and to calculate the nonlinear absorption coefficient.

Linear absorption spectra of the samples were measured using a UV-VIS (Cary 300 Bio) spectrophotometer (Figure 2(a)). For these measurements, concentrations of approximately $1.4 \times 10^{-4}$ and $1 \times 10^{-5} \mathrm{~mol} \mathrm{l}^{-1}$ were used for the oxide samples and $\mathrm{C}_{60}$, respectively. According to the absorption spectra, ferrite samples do not show definite absorption peaks. However, assuming direct band gap, the band gap energies can be determined from the absorption coefficients $(\alpha)$ near the band edge by using the Tauc relation ${ }^{17,18}$

$$
\alpha \mathrm{h} v=\mathrm{A}\left(\mathrm{h} \nu-\mathrm{E}_{\mathrm{g}}\right)^{\frac{1}{2}},
$$

where $\mathrm{A}$ is a constant that depends on the band structure and the refractive index of the material, $h$ is the Planck's 

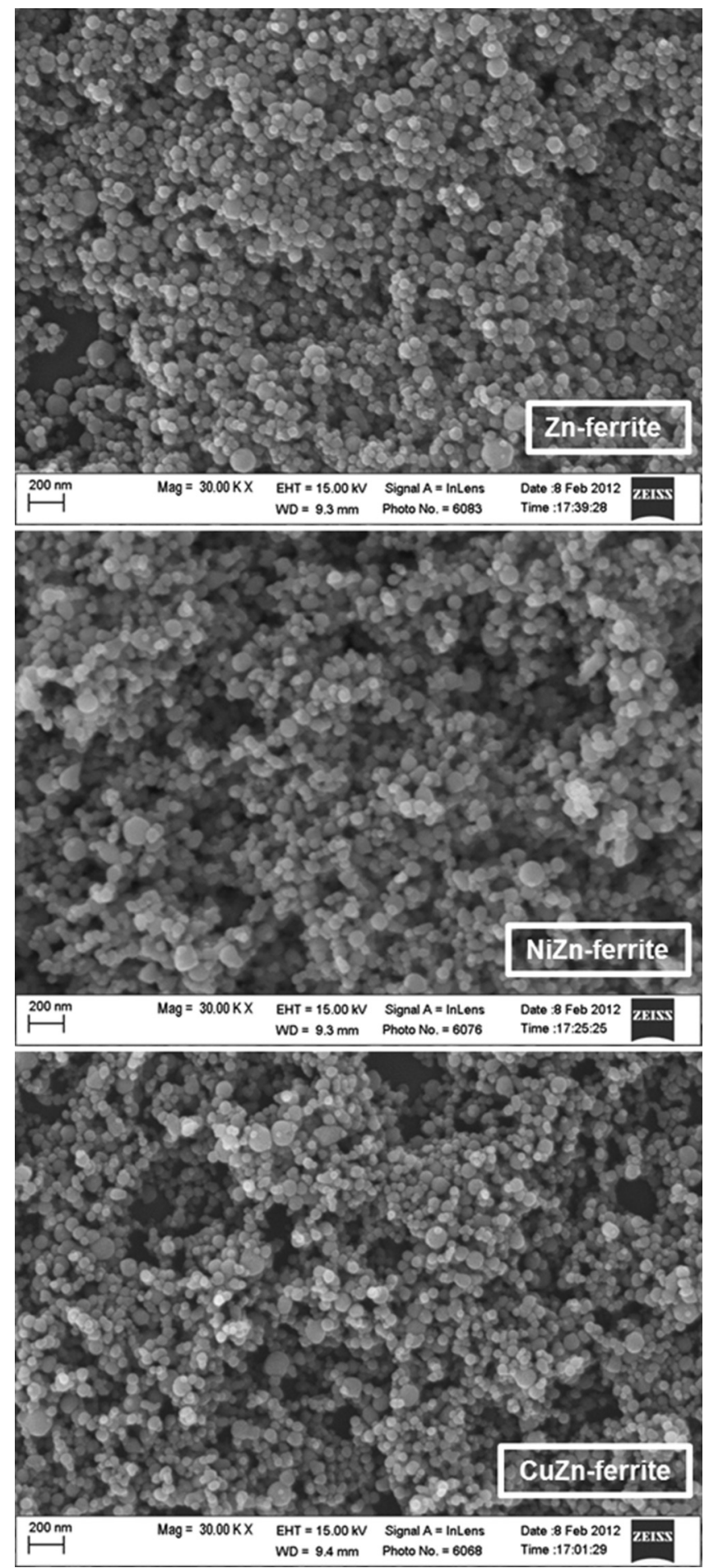

FIG. 1. $\mathrm{SEM}$ images of $\mathrm{ZnFe}_{2} \mathrm{O}_{4}, \mathrm{NiZnFe}_{2} \mathrm{O}_{4}$, and $\mathrm{CuZnFe}_{2} \mathrm{O}_{4}$.

constant, $\nu$ is the frequency, and $E_{g}$ is the energy gap. By plotting $(\alpha h \nu)^{2}$ versus $h v$, the band gap energy was determined by extrapolation, as shown in Figure 2(b). The values obtained are 2.3, 2.1, and $2.5 \mathrm{eV}$, for $\mathrm{ZnFe}_{2} \mathrm{O}_{4}, \mathrm{NiZnFe}_{2} \mathrm{O}_{4}$, and $\mathrm{CuZnFe}_{2} \mathrm{O}_{4}$, respectively.

Samples for optical limiting measurements were prepared by dispersing the nanoparticles in $0.005 \mathrm{~g} \mathrm{ml}^{-1}$ solutions of poly(methyl methacrylate) (PMMA) in toluene. The addition of PMMA helps to stabilize the dispersion. Samples were so prepared that each has the same linear transmission of approximately $52 \%$ at the excitation wavelength of
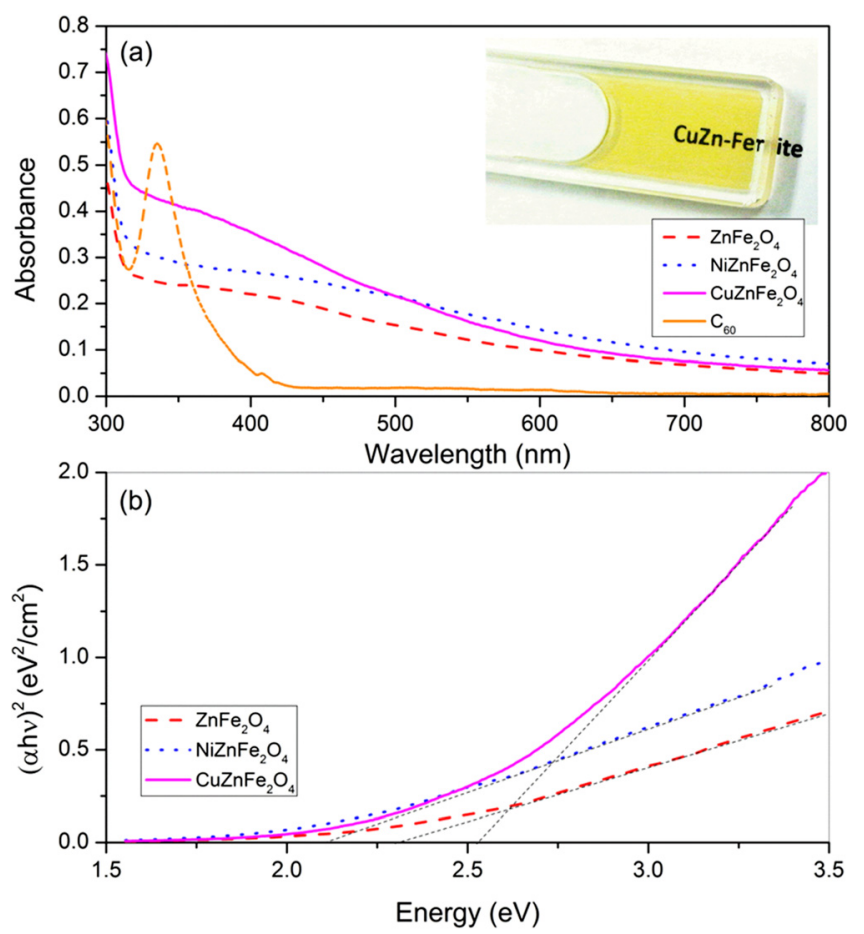

FIG. 2. (a) Absorption spectra of the samples. Inset shows $\mathrm{CuZnFe}_{2} \mathrm{O}_{4}$ sample of $52 \%$ linear transmission. (b) Tauc plots for calculating the bandgap energies.

$532 \mathrm{~nm}$, when taken in $1 \mathrm{~mm}$ path length cuvettes (inset of Figure 2(a)). An Nd:YAG laser (Minilite I, Continuum) emitting $5 \mathrm{~ns}$ laser pulses was used as the excitation source. The laser pulse repetition frequency was $0.2 \mathrm{~Hz}$. The laser beam was passed through an iris aperture and pinhole to obtain a clean Gaussian beam. In the open aperture Z-scan, the laser beam is focused using a lens, and the transmission of the sample is measured as a function of the relative position of the sample $(z)$ with respect to the beam focus $(z=0)$. We used a plano-convex lens $(f=100 \mathrm{~mm})$ for focusing the beam, which had a diameter of about $3 \mathrm{~mm}$. The beam waist at the focal point, as measured by the knife edge method, ${ }^{19}$ is $12 \pm 2 \mu \mathrm{m}$. In our set up, the sample taken in a $1 \mathrm{~mm}$ glass cuvette was mounted on a linear translation stage of $15 \mathrm{~cm}$ span and $1 \mu \mathrm{m}$ resolution (Newport, ILS150PP). The incident and transmitted pulse energies were measured using pyroelectric energy probes (LaserProbe, RjP-735). Z-scans were done at three different incident laser pulse energies, viz. 5, 8, and $12 \mu \mathrm{J}$. The open-aperture $\mathrm{z}$-scan curves measured in the samples at the incident energy of $12 \mu \mathrm{J}$ are shown in Figure 3.

In general, the depth of the valley in the z-scan curve is a direct indication of the optical limiting efficiency of a material. From the $\mathrm{z}$-scans, it is clear that $\mathrm{C}_{60}$ exhibits the maximum dynamic range for optical limiting, as it shows a limiting effect throughout the range of measurement. In contrast, the ferrite samples show an increase in transmission in the low and moderate fluence regions, and a deep, efficient limiting at the higher fluences. The limiting efficiency of $\mathrm{NiZnFe}_{2} \mathrm{O}_{4}$ and $\mathrm{CuZnFe}_{2} \mathrm{O}_{4}$ are better than that of $\mathrm{C}_{60}$ at the highest fluences. Even though $\mathrm{C}_{60}$ offers protection to the detector for the entire range of input fluences, this may in fact become a disadvantage because the sensitivity of the 


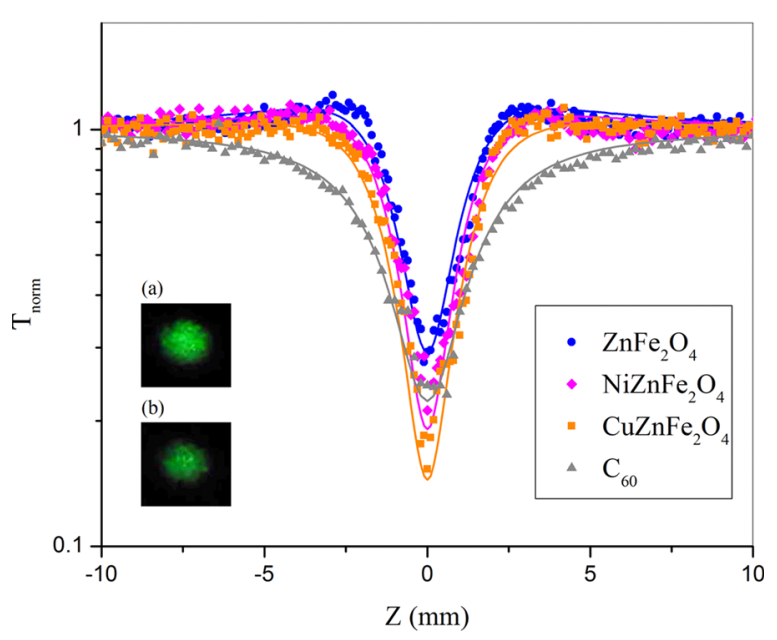

FIG. 3. Open aperture z-scans of the samples. Unlike $\mathrm{C}_{60}$ which shows optical limiting throughout, ferrite samples exhibit absorption saturation at the lower fluences, with a relatively sharper onset of limiting in the higher fluence region. Solid lines are numerical fits to the measured data obtained using Eq. (2). Inset shows photographs of (a) direct and (b) transmitted laser beams in the far field. Thermally induced scattering is not evident in these images.

protected detector is reduced even for those input fluences, which are lower than its damage threshold. Thus from an application point of view, the ferrite samples have a unique advantage: when properly designed, they can retain or even increase the sensitivity of a detector while it is in its safe operating regime, and switch to sudden limiting when the input fluence exceeds the detector damage threshold. Sudden onset of limiting is sometimes an indication of induced thermal scattering; but from visual inspection and photographic images, we have verified that in the present case, thermal scattering is negligible (inset of Figure 3).

The normalized transmission of the samples $T(z)$ can be numerically evaluated using the expression ${ }^{16}$

$$
T=\frac{1}{\sqrt{\pi} q_{0}} \int_{-\infty}^{+\infty} \ln \left(1+q_{0} e^{-t^{2}}\right) d t
$$

with $q_{0}$ given by $\beta I_{0} L_{\text {eff }} /\left[1+\left(z^{2} / z_{0}^{2}\right)\right]$, where $I_{0}$ is the irradiance at the focus, and $z$ is the position of the sample. $z_{0}$ is the Rayleigh range given by $\pi \omega(0)^{2} / \lambda$, where $\omega(0)$ is the beam radius at focus, and $\lambda$ is the light wavelength. $\beta$ is the nonlinear absorption coefficient. $L_{\text {eff }}$ is given by

$$
L_{e f f}=\frac{1-e^{-\alpha L}}{\alpha},
$$

where $\alpha$ is normally the linear absorption coefficient. However, considering the occurrence of kinetic absorption saturation in the ferrite samples, $\alpha$ is rewritten as

$$
\alpha=\frac{\alpha_{0}}{1+\frac{I}{I_{s a t}}}
$$

where $\alpha_{O}$ is the linear absorption coefficient and $I_{\text {sat }}$ is the saturation intensity. Numerical fits obtained to the experimental data using Eq. (2) are shown in Figure 3, and the calculated values of $\beta$ and $I_{\text {sat }}$ are summarized in Table I. In the limited range of pulse energies used, we could not observe any clear dependency of the nonlinear parameters on the energy.

For drawing the optical limiting curves, we note that at any given position $z$, the energy density (fluence) of a spatially Gaussian beam can be calculated from the laser pulse energy and the beam radius. The beam radius $w(z)$ is given by

$$
w(z)=w(0) \sqrt{1+\left(\frac{z}{z_{0}}\right)^{2}},
$$

and knowing $w(z)$, the position-dependent fluence of the Gaussian laser beam can be calculated from the expression,

$$
F(z)=4(\ln 2)^{1 / 2} E_{\text {in }} / \pi^{3 / 2} \omega(z)^{2},
$$

where $E_{\text {in }}$ is the laser pulse energy. From the measured values of the energy transmitted by the samples for different values of $z$, the variation of the output fluence with input fluence can be determined. Figure 4(a) shows the output fluence, and Figure 4(b) shows the sample transmission, plotted against the input fluence. The optical limiting thresholds $F_{t}$ (input fluence at which the transmission drops to $50 \%$ of the linear transmission) are $1.16,1.49,1.60$, and $2.23 \mathrm{~J} \mathrm{~cm}^{-2}$ for $\mathrm{C}_{60}, \mathrm{CuZnFe}_{2} \mathrm{O}_{4}, \mathrm{NiZnFe}_{2} \mathrm{O}_{4}$, and $\mathrm{ZnFe}_{2} \mathrm{O}_{4}$, respectively. In comparison, the limiting thresholds of suspensions of $\mathrm{C}_{60}$, carbon nanotubes, and carbon black, prepared with approximately $50 \%$ linear transmission at $532 \mathrm{~nm}$, for $7 \mathrm{~ns}$ laser pulses, are reported to be $1.0 \mathrm{~J} \mathrm{~cm}^{-2}, 1.7 \mathrm{~J} \mathrm{~cm},{ }^{-2}$ and $1.7 \mathrm{~J} \mathrm{~cm}^{-2}$, respectively. ${ }^{20}$

The observed enhancement in optical limiting efficiency when $\mathrm{Cu}$ or $\mathrm{Ni}$ is incorporated into $\mathrm{Zn}$-ferrite can be explained using a mechanism involving self-trapping of charge transfer (CT) states. Optical response of $3 \mathrm{~d}$ metal oxides is dominated by the CT transition between $2 p$ orbital of oxygen and $3 \mathrm{~d}$ orbital of metal. ${ }^{21}$ The relaxation of the optically excited CT state is governed by a cumulative effect of both electronic and ionic terms associated with the displacement of electronic shells and ionic core, respectively. ${ }^{22}$ In a CT unstable system, self-trapping of the CT excited state can occur. This self-trapping mechanism is strongly governed by the lattice strain. ${ }^{23}$ In the case of nickel and copper zinc ferrite, introduction of $\mathrm{Ni}^{2+}$ and $\mathrm{Cu}^{2+}$ ion into the $\mathrm{Zn}$ ferrite structure can create a distortion in the crystal field and induce strain within the structure. It may be noted that these added ions occupy either the tetrahedral site or octahedral site of the structure depending upon whether the fabrication

TABLE I. Nonlinear absorption coefficient $(\beta)$ and saturation intensity $\left(I_{\text {sat }}\right)$ calculated for the samples at incident laser pulse energies of 5,8 , and $12 \mu \mathrm{J}$, respectively.

\begin{tabular}{lccccccc}
\hline \hline & \multicolumn{2}{c}{$\beta\left(\times 10^{-10} \mathrm{~m} \mathrm{~W}^{-1}\right)$} & & \multicolumn{2}{c}{$I_{\text {sat }}\left(\times 10^{11} \mathrm{~W} \mathrm{~m}^{-2}\right)$} \\
\cline { 2 - 3 } \cline { 6 - 8 } Sample & $5 \mu \mathrm{J}$ & $8 \mu \mathrm{J}$ & $12 \mu \mathrm{J}$ & & $5 \mu \mathrm{J}$ & $8 \mu \mathrm{J}$ & $12 \mu \mathrm{J}$ \\
\hline $\mathrm{ZnFe}_{2} \mathrm{O}_{4}$ & 5 & 5.1 & 5 & & 4.6 & 5.5 & 5 \\
$\mathrm{NiZnFe}_{2} \mathrm{O}_{4}$ & 6.2 & 6 & 5.8 & & 4.8 & 5.5 & 5 \\
$\mathrm{CuZnFe}_{2} \mathrm{O}_{4}$ & 8 & 7.2 & 7.9 & & 5.2 & 5.2 & 5.2 \\
$\mathrm{C}_{60}$ & 5.9 & 4.8 & 4.8 & & $\mathrm{a}$ & $\mathrm{a}$ & $\mathrm{a}$ \\
\hline \hline
\end{tabular}

${ }^{\mathrm{a}}$ The best numerical fit to the $\mathrm{C}_{60}$ data was obtained without the $I_{\text {sat }}$ term. 

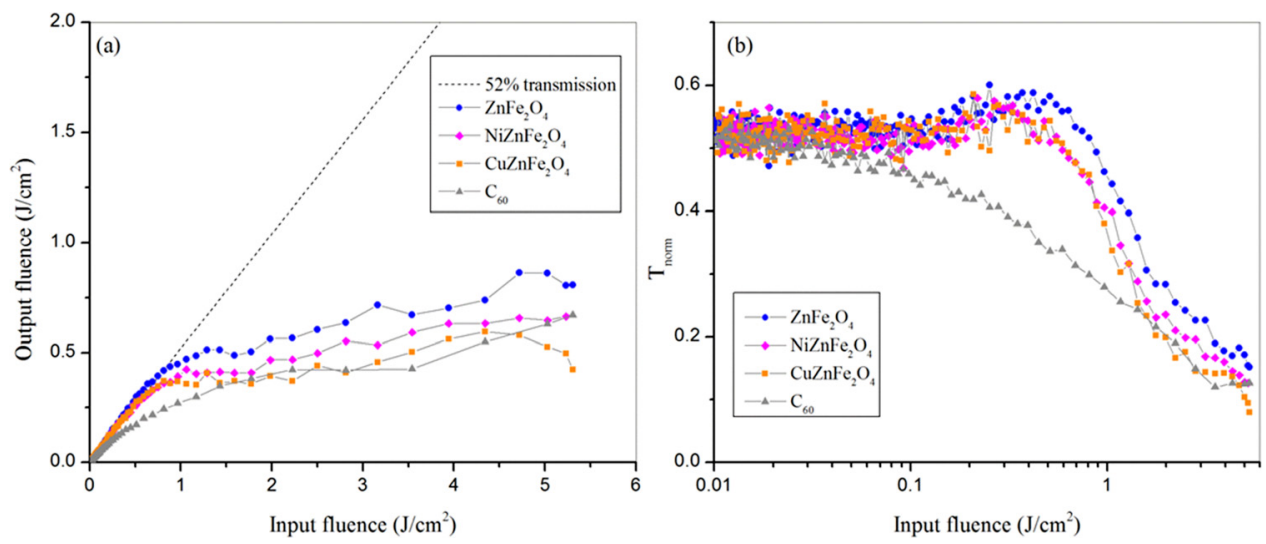

FIG. 4. Optical limiting performance of the samples. (a) Output fluence and (b) normalized transmission plotted against input laser fluence. Lines connecting data points are guides to the eye. method favors normal spinel or inverse spinel. The induced strain enhances self-trapping of the CT states, which results in an increase in excited state life time, and therefore the excited state absorption coefficient. Considering also the fact that thermal scattering is not significant in the samples, it can be concluded that optical limiting observed in these ferrites is related to a reverse saturable absorption (RSA) mechanism involving excited electronic states.

In conclusion, we have investigated optical limiting properties of the spinel ferrite system $\mathrm{ZnFe}_{2} \mathrm{O}_{4}$ and its mixed forms $\mathrm{NiZnFe}_{2} \mathrm{O}_{4}$ and $\mathrm{CuZnFe}_{2} \mathrm{O}_{4}$ at $532 \mathrm{~nm}$ using nanosecond laser pulses. Addition of $\mathrm{Ni}$ and $\mathrm{Cu}$ into the crystalline structure results in an enhanced limiting efficiency, which is attributed to the self-trapping of the charge transfer state, and the resultant increase in excited state absorption. All three samples show moderate absorption saturation at lower input fluences and steep limiting at higher input fluences. In comparison, $\mathrm{C}_{60}$ exhibits limiting throughout the fluence range of investigation. The sudden onset of optical limiting preceded by absorption saturation in the present ferrite samples will be advantageous in critical applications where the sensitivity of the protected detector needs to be retained at the maximum value until the input light fluence reaches the detector damage threshold.

Authors thank Dr. Binh Duong (NSTC) and Kirk Scammon of Material Characterization Facility at UCF for their assistance with the TEM images.

${ }^{1}$ C. Altavilla and E. Ciliberto, Inorganic Nanoparticles: Synthesis, Applications, and Perspectives (Taylor \& Francis Group, 2010).

${ }^{2}$ O. V. Prezhdo, Acc. Chem. Res. 42, 2005 (2009).

${ }^{3}$ M. O. Ramirez, A. Kumar, S. A. Denev, N. J. Podraza, X. S. Xu, R. C. Rai, Y. H. Chu, J. Seidel, L. W. Martin, S. Y. Yang, E. Saiz, J. F. Ihlefeld,
S. Lee, J. Klug, S. W. Cheong, M. J. Bedzyk, O. Auciello, D. G. Schlom, R. Ramesh, J. Orenstein, J. L. Musfeldt, and V. Gopalan, Phys. Rev. B 79, 224106 (2009).

${ }^{4}$ S. S. Nair, J. Thomas, C. S. S. Sandeep, M. R. Anantharaman, and R. Philip, Appl. Phys. Lett. 92, 171908 (2008).

${ }^{5}$ C. He, B. Zou, Z. Wu, and Y. Nie, Opt. Commun. 281, 851 (2008).

${ }^{6}$ A. Goldman, Modern Ferrite Technology, 2nd ed. (Springer, 2006).

${ }^{7}$ J. D. Adam, L. E. Davis, G. F. Dionne, E. F. Schloemann, and S. N. Stitzer, IEEE Trans. Microwave Thoery Tech. 50, 721 (2002).

${ }^{8}$ H. M. Joshi, Y. P. Lin, M. Aslam, P. V. Prasad, E. A. Schultz-Sikma, R. Edelman, T. Meade, and V. P. Dravid, J. Phys. Chem. C 113, 17761 (2009).

${ }^{9}$ R. Hao, R. Xing, Z. Xu, Y. Hou, S. Gao, and S. Sun, Adv. Mater. 22, 2729 (2010).

${ }^{10}$ M. Arruebo, R. Fernández-Pacheco, M. R. Ibarra, and J. Santamaría, Nanotoday 2, 22 (2007).

${ }^{11}$ J. M. Perez, F. J. Simeone, Y. Saeki, L. Josephson, and R. Weissleder, J. Am. Chem. Soc. 125, 10192 (2003).

${ }^{12}$ J. M. Hastings and L. M. Corliss, Rev. Mod. Phys. 25, 114 (1953).

${ }^{13}$ M. P. Joshi, S. R. Mishra, H. S. Rawat, S. C. Mehendale, and K. C. Rustagi, Appl. Phys. Lett. 62(15), 1763-1765 (1993).

${ }^{14}$ S. Couris, E. Koudoumas, A. A. Ruth, and S. Leach, J. Phys. B 28, 4537 (1995).

${ }^{15}$ D. M. Guldi and M. Prato, Acc. Chem. Res. 33, 695 (2000).

${ }^{16}$ M. Sheik-Bahae, A. A. Said, T. H. Wei, D. J. Hagan, and E. W. Van Stryland, IEEE J. Quantum Electron. 26, 760 (1990).

${ }^{17}$ J. Tauc, R. Grigorovici, and A. Vancu, Phys. Status Solidi B 15, 627 (1966).

${ }^{18}$ G. Joshi, N. Saxena, R. Mangal, A. Mishra, and T. Sharma, Bull. Mater. Sci. 26, 387 (2003).

${ }^{19}$ Y. Suzaki and A. Tachibana, Appl. Opt. 14, 2809 (1975).

${ }^{20}$ P. Chen, X. Wu, X. Sun, J. Lin, W. Ji, and K. L. Tan, Phys. Rev. Lett. 82, 2548 (1999).

${ }^{21}$ B. Fromme, D-d Excitations in Transition-Metal Oxides: A SpinPolarized Electron Energy-Loss Spectroscopy (SPEELS) Study (Springer, 2001).

${ }^{22}$ A. M. Stoneham, J. Gavartin, A. L. Shluger, A. V. Kimmel, D. M. Ramo, H. M. Rønnow, G. Aeppli, and C. Renner, J. Phys. Condens. Matter 19, 255208 (2007).

${ }^{23}$ R. V. Pisarev, A. S. Moskvin, A. M. Kalashnikova, and Th. Rasing, Phys. Rev. B 79, 235128 (2009). 